\title{
The Correlation Between mRNA Hedgehog (Hh) Gene Expression with the Growth of Length of Tissue Regeneration Digit Tip Mice (Mus musculus) Post Amputation
}

Corresponding Author:

Syafruddin llyas

Syafruddin6@usu.ac.id

Received: 1 February 2020

Accepted: 8 February 2020

Published: 16 February 2020

Publishing services provided by

Knowledge E

(c) Titta Novianti et al. This article is distributed under the terms of the Creative Commons

Attribution License, which

permits unrestricted use and

redistribution provided that the

original author and source are

credited.

Selection and Peer-review under the responsibility of the IC-BIOLIS Conference Committee.
Titta Novianti ${ }^{1}$, Muhammad Panji Januarsyah Kustiawan ${ }^{1}$, Blandina Ivanka Pinkan Manimpurung ${ }^{1}$, Muhammad Ichsan ${ }^{1}$, Alfero Putra Iriyanto ${ }^{1}$, Febriana Dwi Wahyuni ${ }^{1}$, It Jamilah², and Syafruddin Ilyas ${ }^{2}$

${ }^{1}$ Biotechnology Department, Faculty of Health Sciences, Universitas Esa Unggul, Jakarta

${ }^{2}$ Biology Department, Faculty of Mathematic and Sciences, Universitas Sumatera Utara, Medan

\section{Abstract}

Mice can regenerate tissue in the third phalanges of digit tip after amputation. The tissue regeneration process involved various cells, molecules, proteins, and genes that were thought to have a role in the process. Hedgehog $(\mathrm{Hh})$ gene was thought to have a role in tissue regeneration, but research in adult tissue regeneration was limited. $\mathrm{Hh}$ gene had a role in mitosis and cell morphogenesis during the embryo growth. The expression of this gene continued in the adult cell population. We analyzed the Hh gene expression in tissue regeneration of the third phalange digit tip mice post-amputation until day 25. We used 30 males of mice (Mus musculus var Webster) as an animal model. We observed the histological analysis and Hh gene expression in each growth day. Spearman correlation test results in a strong and significant correlation between the growth length of digit tip mice and mRNA expression of the Hh gene $(p<0.005$; $r$ $=0.874)$.

Keywords: Hedgehog, tissue regeneration, digit tip, proliferation,

\section{Introduction}

Tissue regeneration is a complex process that involves cells, genes, proteins, and molecules from the inflammatory process until the tissue regeneration process completed. [1--4] Tissue regeneration process includes four phases, ie. The wound-healing phase, blastema phase, regeneration phase, and maturation phase. The wound healing phase involves the inflammation stage, granulation stage, and wound contraction stage that occurred in 10 days. In the inflammatory stage, the tissue tried to stop the flow of blood to the injury area by the clot of compacted fibrin. This blood-clotting requires the factor of blood clotting and platelets. In the inflammatory stage, neutrophils and 
basal lamina proliferated and differentiated to form new tissue.[5--7] After the inflammation ended, granulation cells occurred in the blastema phase. The granulated cells formed the new tissue and entered the maturation phase, this is the last phase. The morphogenesis process occurred in the maturation phase. [8--10]

The ability of tissue regeneration in each animal is different. Animals with a low taxonomic level has higher ability of tissue regeneration compared to animals at high taxonomic levels.[11] Planaria has high regeneration power, lizards have regenerative power but are limited only to their tails.[12] Likewise, mice have limited regeneration power only at the third phalanges.[13, 14] The ability of this regeneration power occurs because of the limitations of cells, molecules, genes, and proteins whose activity is lower.[15]

Research of tissue regeneration is an effort to find the right therapy for humans and stimulate the regeneration of tissue when they get an injury or amputation in their organs. The aim of this research is finding the gene or protein that has an important role in tissue regeneration. Hedgehog $(\mathrm{Hh})$ gene has a role in cell mitosis and tissue morphogenesis from the embryogenesis periodic until the development of adulthood in all organisms.[16] The expression of these genes is still unlimited study in some adult cell populations. The study of the role of $\mathrm{Hh}$ gene in tissue regeneration process is limited. There are three types of hedgehog proteins includes sonic hedgehog (SHh), Indian hedgehog $(\mathrm{IHh})$, and desert hedgehog $(\mathrm{DHh})$. The Hh protein will undergo modification after translation and will be secreted by cells using a protein transporter membrane. $\mathrm{SHh}$ protein is most expressed by vertebrate animal cells. Signaling of the SHh gene also regulates the expansion and division of cells in the formation of neural tubes in the embryonic period. At the development stage, SHh protein inhibits the differentiation of neural progenitor cells to keep the cells as progenitor stem cells. The Hh protein signaling regulates the stem cells in terms of proliferation and specifications cells. In the adult vertebrate, $\mathrm{Hh}$ signaling wounds can trigger stem cells to repair and differentiate. Increased of $\mathrm{Hh}$ regulation is a natural response to injury which is a way to achieve tissue repair through cell proliferation, plasticity, or transdifferentiation.[16, 17]

The ability of regeneration in the third phalanges of digit tip mice can be used as an animal model to see the role of the $\mathrm{Hh}$ gene in tissue regeneration. In this study, we analyze the correlation between the Hh gene expression in digit tip mice tissue and the growth length of digit tip mice to analyze the role of the Hh gene in the tissue regeneration process. 


\section{Methods}

\subsection{Sample}

We used 30 males of mice (Mus musculus var Webster) as an animal model, eight weeks old, and twenty grams body weight. Mice were maintained and adapted in the research and development laboratory, Ministry of Health, Republic of Indonesia. Samples were regenerated tissue of digit tip mice (Mus musculus) on days $0,1,3,5,10,15$, until day 25 after amputation. The code of ethics permitted from the ESA Unggul University Research

Ethics-Commission.

\subsection{Histology with an outward appearance of Haematoxylin Eosin (HE)}

Histology preparations were stained with haematoxylin-eosin (HE) strokes and histochemcal: 10\% formalin; 70\% alcohol; 80\% alcohol; alcohol 95\%; and 100\% alcohol; xylol; paraffin block; haematoxylin-eosin; equates; the outward appearance of Van Gielson.

\subsection{The measured growth length of digit tip mice}

The measured growth length of digit tip mice used the Image-J program I-46. Image-J 1-46 software has various features that one feature can use in measuring the length of tissue in $\mu \mathrm{m}$ scale.[18] The length calculation which used the line drawing feature was obtained automatically as the measure feature (Figure 1).

\section{4. qPCR mRNA Analysis}

Before amplified DNA of the Hedgehog gene by qPCR machine, we designed the primary DNA using multiple alignment methods by MEGA7 software. We used 18 sRNA for positive control as the housekeeping gene. Negative controls were free water as a substitute for RNA to get rid of false-positive results. The primary DNA of Hh gene was amplified with DNA isolation from tissue samples by qPCR procedure, through the stages of DNA synthesis, inactivation of Reverse transcriptase, the PCR cycle was carried out 40 cycles with annealing temperature at $57^{\circ} \mathrm{C}$ for the $\mathrm{HH}$ gene and $18 \mathrm{~S}$ rRNA, and subsequently the melting curve stage. The results of GPCR obtained the value of 


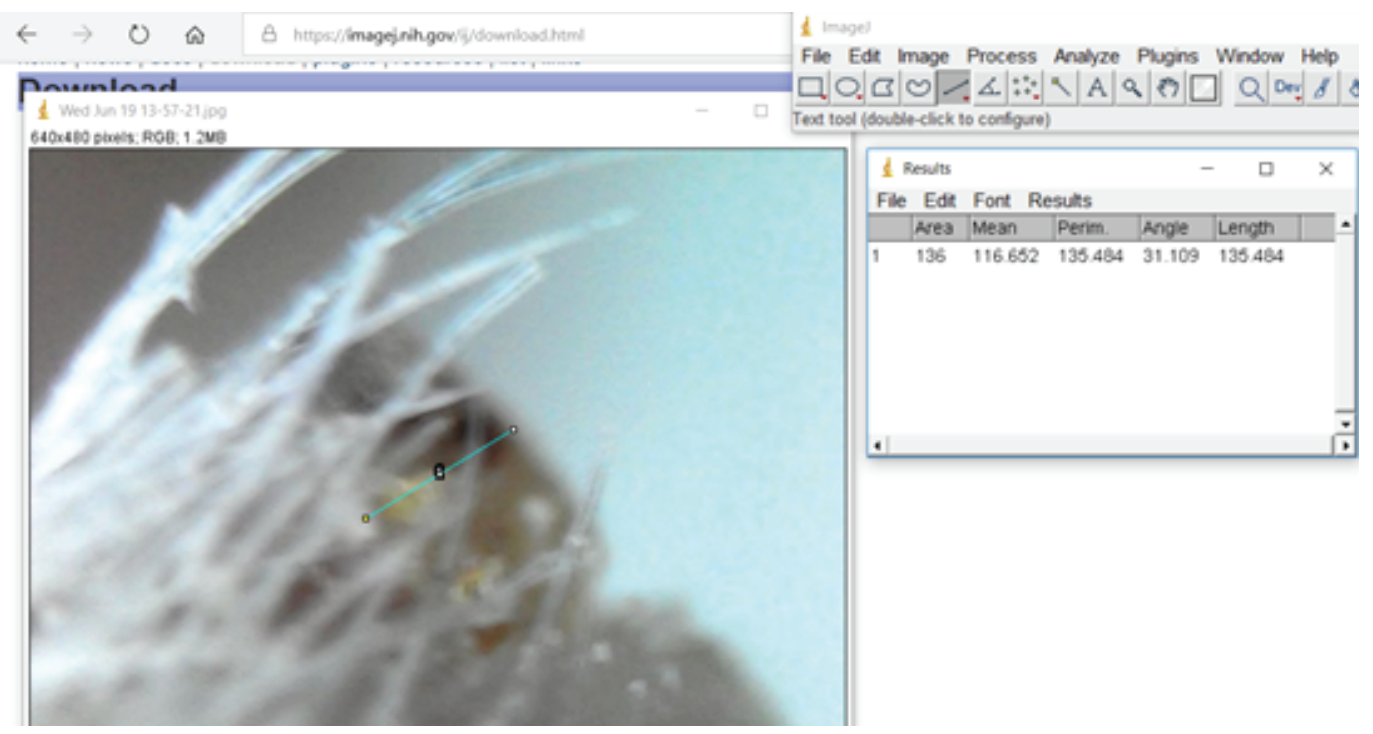

Figure 1: Measurement of digit tip length of mice (Mus musculus) using ImageJ software.

Cycle Threshold (CT) for analysis by the Livak method. The value of gene expression is a relative quantification to the control.

\subsection{Statistical Analysis}

Statistical analysis for normally data distribution was using the Kolmogorov Smirnov test. If the data distribute was not normal would be transformed into a log model. The normality test performed again. We used a parametric model for the data distribution was normal. Conversely, we used the non-parametric model if the data distribution was not normal. We used Spearman's correlation test used for non-parametric data.

\section{Results}

\subsection{Morphology Growth of digit tip Mice}

The results of post-amputation digit tip tissue growth after growth of day 0 (4 hours), days $1,3,5,10,15$, and 25 after amputation, showed significant growth results (Figure 2).

\subsection{The Measurement Results of digit tip mice Length}

The measurement results of digit tip mice length from day 0 ( 4 hours after amputation) until the 25 th day showed a significantly different growth. Digit tip mice length data was 

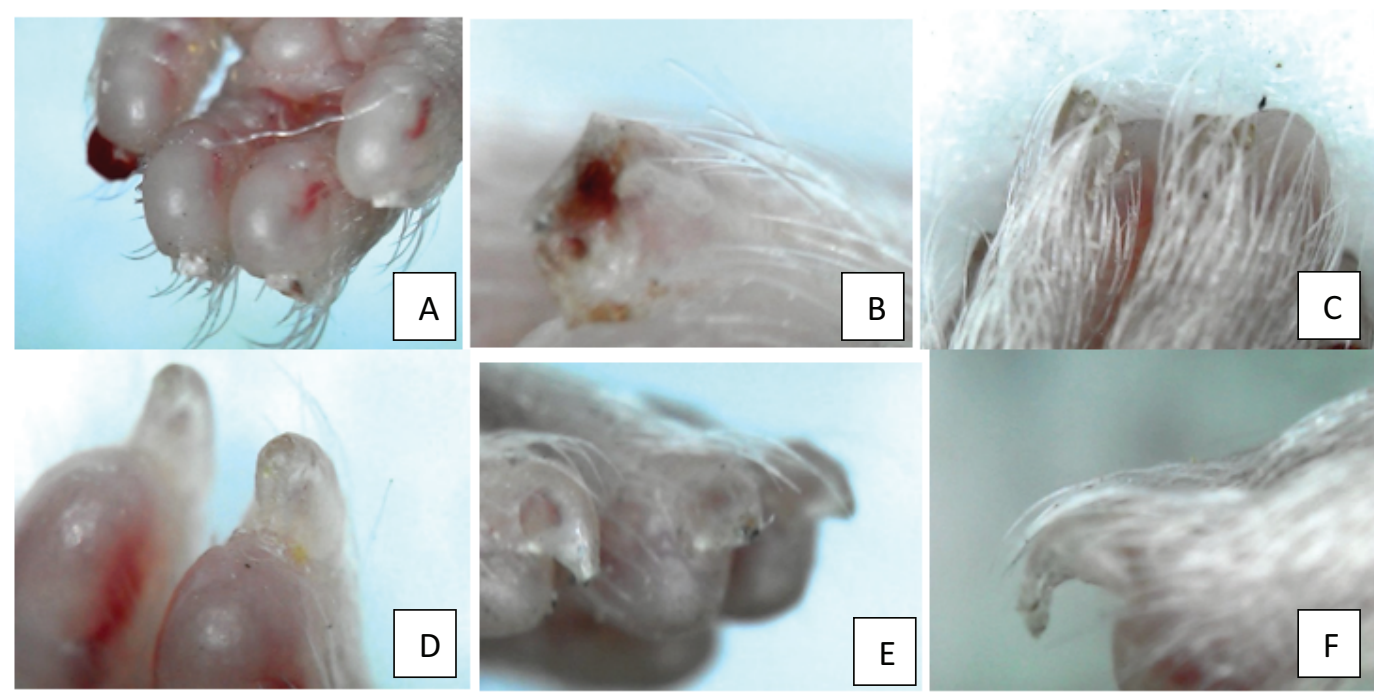

Figure 2: Growth of digit tip mice (Mus musculus) from day $0,3,5,10$, 15, and 25 after amputation. (A) day 0 (4 hours after amputation) (B) day 3 , inflammatory tissue in the wound area (C) day 5 , tissue growth longer (D) day 10, the tissue of digit tip mice begins to form (E) day 15, the tissue of digit tip mice growth thicker $(F)$ day 25 , the morphology of tissue was as a normal.

not normally distributed with the ANOVA non-parametric test $(p<0.05)$ of each growth day (Figure 3). On the graph, it appears that there is a relatively slow growth from day 0 (4 hours after amputation) to day 10 , growth in the length of digit tip mice began to increase rapidly after day 10 to day 25 . Significantly increased growth occurred at the phase after the blastema phase.

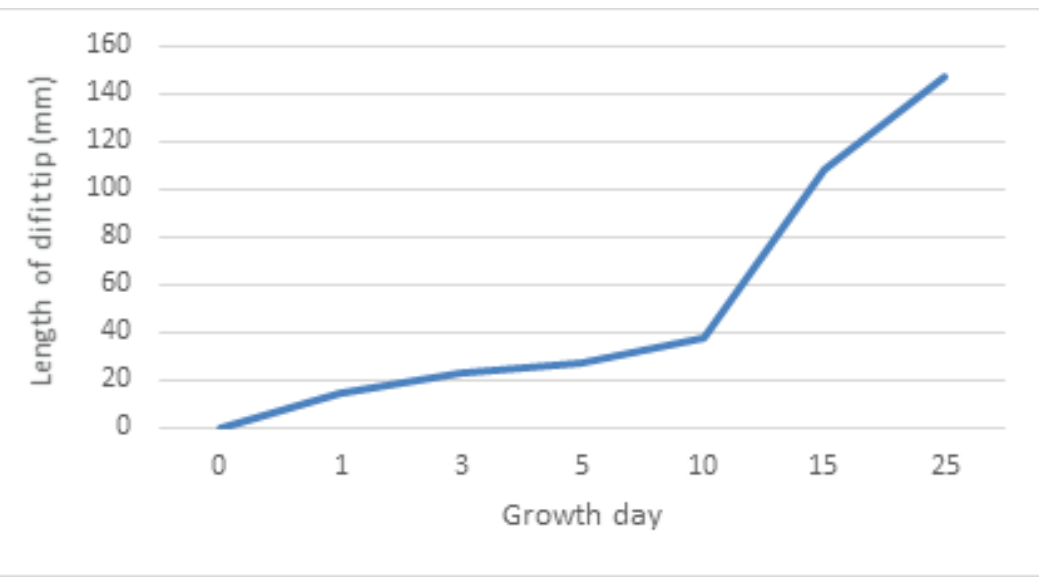

Figure 3: Growth graph of digit tip mice (Mus musculus) from day 0 (4 hours after amputation) until day 25. ANOVA test showed a significant length difference on each growth day $(p<0.05)$. 


\subsection{Hedgehog Gene (HH) mRNA Expression Test Results}

The results of the qPCR test for the analysis of the Hedgehog gene mRNA expression showed a significant difference, the data were not normally distributed, with the nonparametric ANOVA test $(p<0.05)$ (Figure 3$)$. The HH gene mRNA expression graph shows a slow increase from day 0 to day 5 , in the inflammatory phase. The increase in expression begins in the granulation phase until the regeneration phase after the blastema phase. However, this graph decreases in the maturation phase of digit tip mice regeneration.

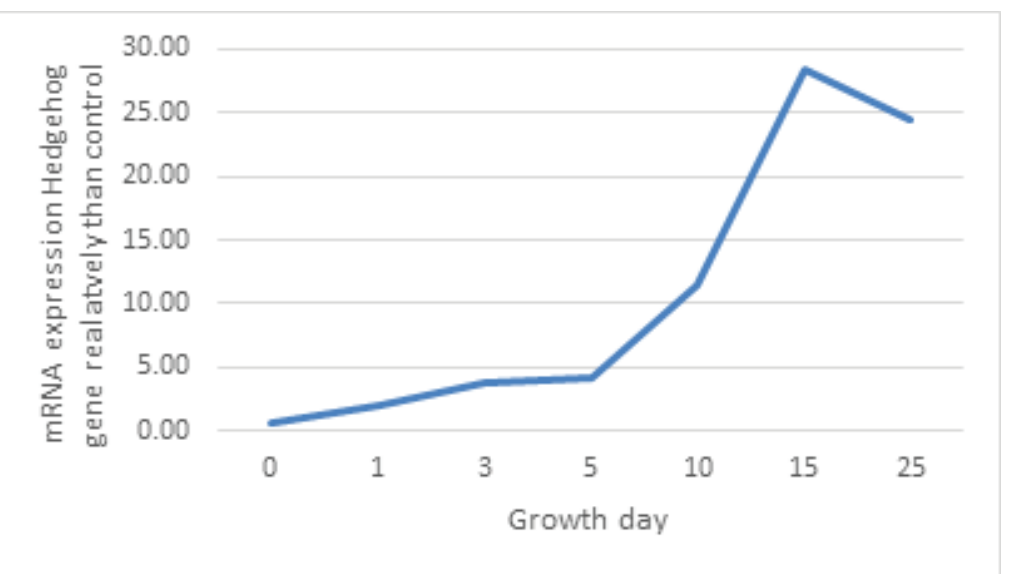

Figure 4: The Graph of mRNA Hedgehog $(\mathrm{Hh})$ gene expression in tissue regeneration process of digit tip mice from day 0 (4 hours after amputation) until day 25.

\subsection{Statistical Analysis}

The results of the Spearman correlation statistical test showed a strong positive correlation between digit tip mice growth and Hedgehog $(\mathrm{Hh})$ mRNA expression $(p<0.005$, $r=0.874$ ) (Figure 5 and Table 1).

\section{Discussion}

The results of the statistical analysis of the digit tip mice length growth from day 0 (4 hours after amputation) until day 25 showed a significant difference in each phase of tissue regeneration. In the inflammatory stage, the length growth of digit tip mice shown no significant. The wound healing and wound contraction occurred in this stage, there was no regenerated tissue but only proliferation, migration, and differentiation cells. Therefore, the growth of the length of digit tip mice in this stage was relatively slow. According to Mescher, wound-healing phase occurred at the beginning of tissue 


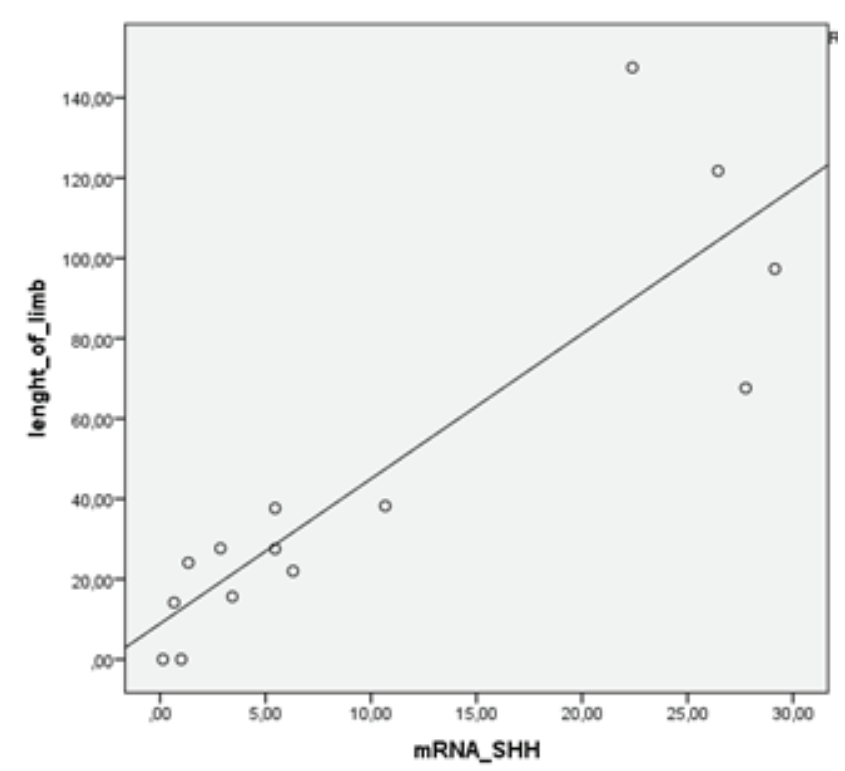

Figure 5: Correlation graph between Hedgehog mRNA expression with digit tip length of mice (Mus musculus).

TABLE 1: Spearman correlation test results between the Hedgehog gene $(\mathrm{HH})$ mRNA expression and digit tip mice growth length $(p<0.05, r=0.874)$.
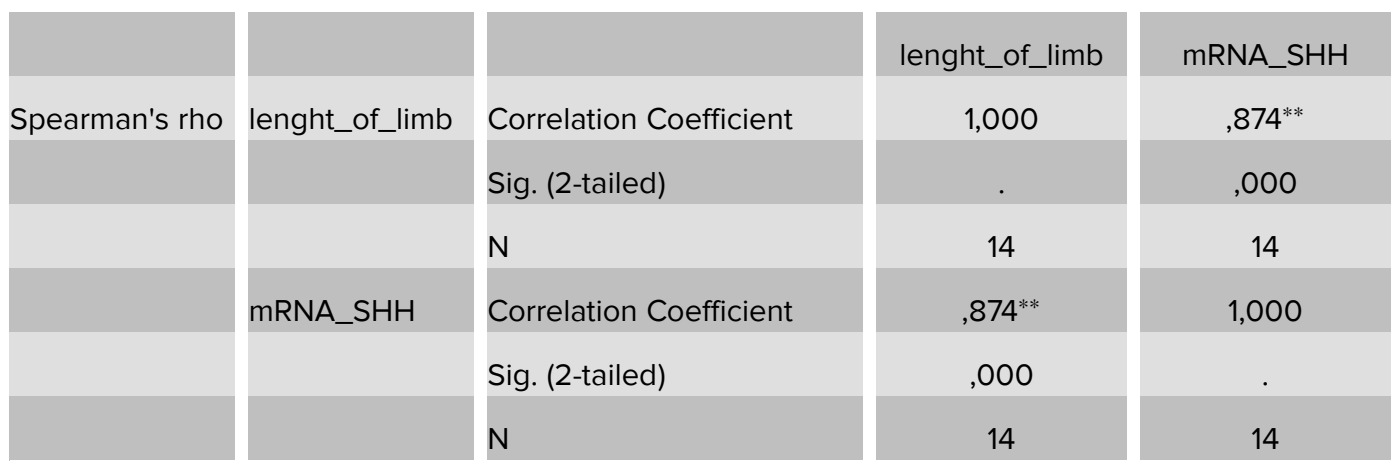

**. Correlation is significant at the 0.01 level (2-tailed).

regeneration, characterized by proliferation, migration, and differentiation of cells.[20] In the tissue regeneration of zebrafish tissue, cells migrated at the beginning of tissue regeneration in various organs. In zebrafish heart tissue regeneration, progenitor cells and cardiomyocytes migrated to the heart tube.[22] The leukocyte cells, fibroblastlike cells, basal lamina, nerve, cartilage, and muscle cells spread in the dermis and connective tissues in tissue regeneration of lizard tail.[23]

The expression of the Hedgehog gene did not increase significantly in the inflammatory phase. After day 5 in the wound-healing phase, the Hh gene expression increased significantly. We suspected that the Hh gene had a role in the proliferation of stem cells after the inflammatory stage. According to Petrova and Joyner, the Hh gene spread and 
expressed in stem cells after the embryonic phase.[16] The Hh gene suspected played a role in the proliferation of cells of adult tissue when injured.

The length of digit tip mice grew significantly after day 10. In this phase, the blastema cells started to form the new tissue by differentiating and proliferating the cells. The rapid and significant growth of digit tip tissue indicated the high activity of the formation of new tissue. Formation of bone tissue, muscle tissue, connective tissue, nerves, dermis, nail, and new blood vessel tissue occurred in the tissue regeneration phase after the blastema phase. The Hh gene mRNA expression increased significantly in this phase. We suspected that the increased of the Hh correlated with differentiation and morphogenesis cells in tissue regeneration of digit tip mice after amputation. The results of Schnapp et al (2005) research showed the role of the Hh gene in the proliferation and differentiation of blastema cells in tissue regeneration of axolotl. The transduction of Hh protein signals stimulated the expression of another gene that plays a role in tissue regeneration.[9] The expression of Hh gene mRNA decreased in the tissue of digit tip mice at the last of our observation, which indicated the decrease of Hh gene expression correlated with the cell proliferation and differentiation been completed. The tissue of digit tip mice has formed.

The result of the Spearman correlation test showed a strong positive correlation between the length growth of the digit tip mice and the mRNA Hh gene expression. The strong correlation showed the role of the $\mathrm{Hh}$ gene in tissue regeneration of digit tip mice. The graph of digit tip mice growth length was significantly after the blastema phase, as well as the $\mathrm{Hh}$ gene expression. The results of this correlation analysis test further strengthen our assumptions about the role of the $\mathrm{Hh}$ gene in the process of tissue regeneration.

\section{Conclusion}

There was an increase of $\mathrm{Hh}$ gene expression in tissue regeneration. There was also a strong correlation between the Hh gene expression with the growth of the length of digit tip mice. Therefore, this research showed that the Hh gene had a significant role in tissue regeneration of digit tip mice. 


\section{Acknowledgment}

Thank you to the Ministry of Research and Technology of Higher Education (Kemenristek DIKTI) had given the funding of PKPT research grant in 2019-2020. Thanks to the Republic of Indonesia Research and Development Agency for permission to maintenance the mice during the research.

\section{References}

[1] Krafts KP. The hidden drama Tissue repair. Organogenesis. 2010; 6(4): 225--33.

[2] Nakatani Y, Kawakami A, Kudo A. Cellular and mollecullar processes of regeneration with special emphasis on fish fins. Dev growth Differ. 2007; 49: 145-54.

[3] Marrero L, Simkin J, Sammarco M \& Muneoka K. Fibroblast reticular cells engineer a blastema extracellular network during digit tip regeneration in mice. Wiley Regeneration. 2017; 4: 69-84. DOI:10.1002/reg2.75.

[4] Mescher AL. Macrophages and fibroblasts during inflammation and tissue repair in models of organ regeneration. Willey regeneration. 2017; 4:9-53. DOI: 10.1002/reg2.77.

[5] Calve S \& Simon H. Biochemical and mechanical environment cooperatively regulate skeletal muscle regeneration. The FASEB Journal. 2012: 2538-2548.

[6] Fernando WA, Leininger E, Simkin J, Li N, Malcolm CA, Sathyamoorthi S, Han M, \& Muneoka K. Wound Healing and blastema formation in regenerating digit tips of adult mice. Developmental Biology. 2011;350: 301-310.

[7] Pintoa R, Godwina JW, Alexander R \& Rosenthala NA. Macrophages are required for adult salamander limb regeneration. 2013. PNAS; vol. 110 (no. 23): 9415--9420.

[8] Petrova R, Joyner AL.Roles for Hedgehog signaling in adult organ homeostasis and repair. Development. 2014. 141: 3445-3457. doi:10.1242/dev.083691.

[9] Schnapp E, Kragl M, Rubin L, Tanaka EM. Hedgehog signaling controls dorsoventral patterning, blastema cell proliferation and cartilage induction during axolotl tail regeneration.Development. 2005. 132 (14): 3243-3253.

[10] Simkin J, Han M, Yu L, Yan M \& Muneoka K. The Mouse Digit Tip: From Wound Healing to Regeneration. Article in Methods in Molecular Biology (Clifton, N.J.) Source: PubMed. 2013: 414-435. DOI: 10.1007/978-1-62703-505-7_24

[11] Wynn TA \& Vannella KM. Macrophages in Tissue Repair, Regeneration, and Fibrosis. Immunity. 2016; 44: 450-462. 
[12] Panigrahya D, Kalisha BT, Huang S, Bielenberga DR, Lea HD, Yangh J, Edini ML et al. Epoxyeicosanoids promote organ and tissue regeneration. PNAS. 2013; vol. 110 (33): 13528--13533.

[13] The blastema and epimorphic regeneration in mammals Ashley W. Seiferta, Ken Muneokab, Developmental Biology 433 (2018) 190--199

[14] Guedelhoefer OC and Alvarado AS. Amputation induces stem cell mobilization to sites of injury during planarian regeneration. Development. 2012;139(19): 3510-3520. DOI: $10.1242 /$ dev.082099.

[15] Lozito TP and Tuan RS. Lizard tail skeletal regeneration combines aspects of fracture healing and blastema-based regeneration. Development. 2016; 143(16):2946--2957. DOI: $10.1242 / \mathrm{dev} .129585$

[16] Londono R, Wenzhong W, Wang B, Tuan RS. Cartilage and Muscle Cell Fate and Origins during Lizard Tail Regeneration. Frontiers Bioengeneering and Biotechnology. 2017; 5(70):1--9. DOI: 10.1242/dev.129585.

[17] Reinke JM and Sorg $H$. Wound repair and regeneration. European Surgical Research.2012; 49(1):35-43. DOI:10.3390/ijms15011647.

[18] Ramadhani D, Kurnia I, Soetopo S, Tetriana D, Ramli I, Budiningsih, Andrijono, Kurjana T, Tobing MDL. Analisis Serta Stitching Citra Imunohistokimia Mib-1 Dengan Immunoratio dan perangkat lunak Nish Element. Lokakrya komputansi dala sains dan Teknologi Nuklir. 2012;(October): 187-97

[19] Tahrin Mahmood P-CY. Western Blot: Technique, Theory, and Trouble Shooting. NAm J Med Sci. 2012;4(9):429--34.

[20] Mescher AL. Macrophages and fibroblasts during inflammation and tissue repair in models of organ regeneration. 2017;(March): 39--53.

[21] Shi $X$ and Garry DJ. Muscle stem cells in development, regeneration, and disease. Genes and Development. 2006; 20(13): 1692-1708. DOI: 10.1101/gad.1419406Guedelhoefer OC and Alvarado AS. Amputation induces stem cell mobilization to sites of injury during planarian regeneration. Development. 2012;139(19): 3510-3520. DOI: 10.1242/dev.082099.

[22] Novianti T, Juniantito V, Jusuf AA, Arida EA, Jusman SA, Sadikin M. Expression and role of HIF-1 $\alpha$ and HIF-2 $\alpha$ in tissue regeneration: a study of hypoxia in house gecko tail regeneration. Organogenesis. 2019. 15(3): 69-84. DOI: 10.1080/15476278.2019.1644889. 